\title{
Toward a Unified Negotiation Framework: Leveraging Strengths in Behavioral and Computational Communities
}

\author{
Nazli Turan ${ }^{\dagger}$, Tinglong Dai ${ }^{\dagger, \dagger \dagger}$, Katia Sycara ${ }^{\dagger \dagger}$, and Laurie Weingart ${ }^{\dagger}$ \\ ${ }^{\dagger}$ Tepper School of Business \\ Carnegie Mellon University \\ Pittsburgh, PA 15213 \\ ${ }^{\dagger \dagger}$ Robotics Institute \\ Carnegie Mellon University \\ Pittsburgh, PA 15213
}

\begin{abstract}
While there has been a large body of negotiation literature in both Behavioral Science (behavioral) and Artificial Intelligence/Game Theory (computational) communities, there has not been an attempt to bridge the two communities to our best knowledge. In this paper, we compare and contrast the characteristics of behavioral and computational literature in negotiation. We discover that incorporating the strengths of two types of literature are valuable in expanding the horizon of research outlook.
\end{abstract}

Key words: Negotiation, multi-disciplinary research

\section{Introduction}

In the last few decades, negotiation has enjoyed generous research interest across disciplines from scholars who have employed methodologies and research agendas from their respective fields to unravel fundamental questions underlying bargaining situations. Political scientists have tried to reconstruct and processanalyze international negotiations between states based on official press releases from the countries (Druckman, 1986); economists have sought to understand the conditions under which negotiators equalize gains given ordinal utility scales (Myerson, 1977); policy-making researchers examined the role of equity for cooperation in international environmental negotiations (Lange and Vogt, 2003); computer scientists are also working on negotiation research, trying to design more intelligent automated negotiation agents (Sycara, 1990; Kraus, 1997). This consistent interest in negotiation speaks not only to the relevance of the concept in different facets of everyday human experience but also to its applicability as a field of scholarly inquiry. It is, however, intriguing that all these different research efforts in the area of negotiation have mostly focused on diverse views among them instead of taking advantage of the informative potential that lies in their convergence. Therefore, the main aim of this paper is to bridge the work of 
two fields that have contributed greatly to research on negotiation: behavioral sciences and computational modeling. Our aim is to delineate both the similarities and differences in how these two fields have conducted negotiation research, their main findings and future directions. To our knowledge, there has not been any prior work to data aiming at an integrated framework of behavioral and computational negotiation literature. Another important purpose of this paper, therefore, is to identify future directions of negotiation research bridging the major strengths of computation and behavior researchers, especially to outline findings relating to the role of culture in negotiation.

In this paper, we have organized our thinking into four categories: utilities, consisting of values, motives and goals; agent-internal states, consisting of the more affective components of the internal reasoning of negotiators such as trust, beliefs and emotions; agent-internal reasoning, which is a cognitive process of encoding, searching and algorithm creation and finally externally-observable behavior and characteristics such as strategies, tactics and outcomes of negotiation. However, before dwelling into these four categories, it is useful to briefly present how the two fields understand and explore negotiation in general terms.

In the behavioral sciences, that is organizational behavior, psychology, social psychology, sociology and behavioral economics, one commonly used definition of negotiation is "a form of conflict behavior, which occurs when two or more parties try to resolve a divergence of interest by means of conversation" (Pruitt and Kim, 2004, pg 56). This general and broad definition perhaps demonstrates the fact that negotiation is one of the most common yet at the same time most complex human activities (Lewicki et al, 1997). People constantly engage in negotiations in their social and professional lives to solve issues that contain both shared and opposed interests (Ury and Fisher, 1981). This means that each negotiation situation contains potential for both competition and cooperation and almost inevitably mutual interdependence (Lewicki et al, 1997).

In the computational literature, there exists similar definitions of negotiation as in the behavior literature. (Braun et al, 2006) define negotiation as "a decentralized decision-making process used to search for and arrive at an agreement that satisfies the requirements of two or more parties in the presence of limited common knowledge and conflicting preferences." The research focus of most of the computational literature, however, is different in that it focuses on providing negotiation support systems (or e-Negotiation systems) to enable automated negotiations between intelligent, autonomous agents, or to design automated negotiation agents to negotiate with human counterparts, or to help and advise negotiators during the various phases during the negotiation process.

It should be noted that there is comparatively more knowledge on negotiation in the behavioral sciences since negotiation has been studied in these fields for a much longer time than it has been in computational sciences. It is also true that since behavioral sciences mainly uses experimental methods with human subjects, interactions between people have been easier to capture. Again, precisely due to these properties of the methods employed, knowledge discovered by behavioral sciences on negotiation has been more complex as it has been possible 
to include or control for multiple factors such as individual differences, evolving structure of the negotiation, possibility of future interaction and so go. Therefore, it will also be very useful to take advantage of the findings from behavioral sciences to inform computational models on negotiation.

\section{Negotiation Research: Different Perspectives}

There exists different ways of classifying negotiation existing research. (Raiffa, $1982)$ propose that negotiation papers can be classified into four categories: (1) symmetrically descriptive, (2) symmetrically prescriptive, (3) asymmetrically prescriptive.descriptive, and (4) externally prescriptive or descriptive. The first category of research focuses on "describing the behavior of all the negotiators, without having any interest whatsoever in prescribing how they should behave". The second category of papers provide advices regarding how each negotiating agents should behave. Such advices are given symmetrically to all the parties. The third is concerned with "studying and understanding the behavior of real people in real conflict situations, so that he can better advise one party about how it should behave in order to achieve its best expected outcome". The last category differs from all the other three in that it addresses the problem of an interventor (e.g., mediator, arbitrator, and rule manipulator) during an negotiation scenario. The research helps interventor manage the negotiating process and achieve better efficiency.

Another way of classifying negotiation research is to look at whether a paper focuses on negotiation process or negotiation outcome. In negotiation literature, a process refers to the events and interactions that occur between parties before the outcome. A process includes all verbal and non-verbal exchanges among parties, the enactment of bargaining strategies and the external and situational events that influence the negotiation (Thompson, 1997). Process analysis in bargaining has mainly focused on either the back and forth exchanges between the negotiators (Adair and Brett, 2005) or on the broader phases of strategic activity over time (Olekans, Brett and Weingart, 2003). A more recent trend has been to examine the "interplay between moment-to-moment actions and reactions exhibited by negotiators within their broader behavioral/strategic context" (Olekans and Weingart, 2008).

Negotiation outcome, on the other hand, is the "product or endpoint of bargaining" such as an agreement, impasse or deadlock (Thompson, 1997). The most general categorization that comes from such analysis of negotiation outcomes and processes is the distinction between competitive and cooperative situations, which is also referred to distributive vs. integrative or hard vs. soft bargaining. Competitive negotiation occurs when "the goals of one party are in fundamental and direct conflict with the goals of the other party" and where "resources are fixed and limited and thus each party wants to maximize his own profit" (Lewicki et al, 1997). On the other hand, cooperative negotiation entails that "goals of the parties are not mutually exclusive" (Lewicki et al, 1997). Thus, in cooperative processes, parties can engage in "positive moments to increase the 
potential gains relative to no agreement" whereas in competitive ones, they utilize moves that "threaten to increase the losses for the other party" (Walcott and Hopmann, 1974). Similarly, in distributive outcomes, a fixed resource is simply divided whereas in integrative outcomes, interests of both parties are satisfied although there may be concessions on both sides (Lewicki et al, 1997).

However, it is also true that it is limiting and challenging to try to divide a complex human interaction like negotiation into these two clear-cut and opposing categories. Thus, a third category, mixed-motive, is used to refer to bargaining situations where parties use a mixture or competitive and cooperative strategies to pursue their interests which usually are competing and compatible at the same time (Fairfield and Allred, 2007).

\section{The Present Framework}

As posited above, the present framework will present four categories: subjective utilities, agent-internal states, agent-internal reasoning and externally-observable behavior.

\subsection{Utilities}

Behavioral Literature In behavioral research, subjective utilities, mainly values, goals and motives in negotiation, are constructed by the individual but are also influenced by the social context that places constraints on these preferences. One of the first models that reflect this phenomenon is the Dual Concern Theory (Pruitt and Rubin, 1986). Although originally developed as a conflict management framework, issues addressed by this model are very much in tandem with those of negotiation and are thus used very often in this arena. The model outlines five basic conflict management strategies: competition, collaboration, compromise, avoidance and accommodation. An individual's choice of the strategy to employ in a conflict situation will be determined as a product of his concern for himself and concern for the other, which can be called self-concern and other-concern. For example, people high in self-concern and low on otherconcern will tend to compete just as those high in both will collaborate or those low in self but high in other concern will tend to accommodate.

Most of the application of the self vs. other concern dichotomy in behavioral negotiation research has been within the framework of social motives, or social value orientations (Deutsch, 1949; Van Lange, 1999). Although these two terms are used almost interchangeably in the literature, the latter is used more commonly to refer to differences in social motives rooted in personality traits whereas the former is used both for situational and individual differences. The main dichotomy in this framework is the prosocial vs. egoistic social motive with the egoistic social motive usually being broken down into individualistic and competitive components. When applied to negotiation, it is expected that prosocials will have the aim to maximize outcomes for both self and others whereas individualistic negotiators will seek to maximize only own outcomes 
and competitive negotiators will try to maximize relative advantage over others (Van Lange, 1999). In other words, prosocials draw positive value from others' outcomes whereas individualists draw none and competitors draw negative value from others' outcomes in negotiation. The implications of these propositions, especially for integrative negotiation, have been empirically tested through multiple studies. In a meta-analysis of 28 studies examining the role of prosocial vs. egoistic motives and resistance to yielding in negotiation, De Dreu, Weingart and Kwon (2000) found that "negotiators were less contentious, engaged in more problem-solving and achieved higher joint outcomes when they had a prosocial rather than egoistic motive" when resistance to yielding was not low. Findings of the authors extend previous work by demonstrating that prosocial negotiators engage in more problem-solving behavior and resort less to conscientious tactics, which is critical because it sheds light on some of the important behavioral mechanisms leading to integrative agreements.

What people value in negotiation is another broad theme that falls under the subjective utilities category. According to the economic models of bargaining that dominated the field in its nascent stages posit that the ultimate aim in negotiation is maximizing one's own outcome and the easiest and most efficient way to realize this aim is through integrative potential (Nash, 1953). However, it is now well-documented in the field that pure economic outcomes are poor indicators of not only what people value in negotiation but also of their behavioral manifestations. Research has shown that perceptions of self, relationship with the other party or the desire to maintain a positive image may be as influential as, if not more, than economic gains. Issues such as self-efficacy, self-esteem, maintaining face or maintaining social relationships with the other party may be of critical concern to the negotiators and subsequently influence processes and outcomes (Bandura, 1977; Synder and Higgins, 1988; Anderson and Shirako, 2008; McGinn and Keros, 2002). The question of what negotiators value and how it influences their perceptions of the outcome has become a fertile area of bargaining research to the extent that Curhan, Elfenbein and Xu (2006) developed and validated a framework to measure subjective value in negotiation. The 16-item Subjective Value Inventory (SVI) includes questions about the perception of the negotiator towards the incremental outcome in terms of satisfaction, loss/win, legitimacy; and feelings about the self, the process and the relationship. The authors also find that the SVI is a more accurate predictor of future negotiation decisions than economic outcomes, which demonstrates again that what people value in negotiation cannot be fully or accurately predicted by sole profit maximization models.

The last main sub-category to be discussed within subjective utilities is goals. At this point, it is important to recognize a possible profusion of terminology in the behavioral science perspective on negotiation. On one hand, goals are used almost interchangeably as motives and are treated in the same way that motives have been described in this paper. For example, there is considerable reference to prosocial or competitive goals in negotiation (De Dreu, 1997). On the other hand, goals are also used to refer to target or aspiration points. Most of the 
work that approaches goals in negotiation from a goal-setting framework would fall under this latter group. A meta-analysis by Zetik and Stuhlmacher (2002) examined the influence of goal setting in negotiation and found a strong effect for difficult goals on higher outcomes on an individual basis.

Computational Literature In the computational literature, few papers discuss subjective utility. Rather most of the computational literature about negotiation provides a clear definition of the utility function. (Fogelman-Soulie, Munier and Shakun 1983) developed an MDP model for the problem of bilateral twoissue negotiation. Instead of assuming bivariate utilities, the one-stage payoff is expressed as a payoff probability distribution representing the probability that a player obtains various amounts of each of the two variables. (Kraus, Wilkenfeld and Zlotkin 1995) discussed different forms of continuous utility functions over all possible outcomes, e.g., time constant discount rates and constant cost of delay. (Zlotkin and Rosenschein 1996) presented an approach to the negotiation problem in non-cooperative domains wherein agents' preferences over different intermediate states are captured by "worth functions" by considering the probabilistic distance between intermediate states and final states. (Rangaswamy and Shell 1997) designed a computer-aided negotiation support system, one part of which is to help negotiating parties disaggregate their own preferences and priorities in order to have a better understanding of them, utilizing several utility assessment techniques. (Faratin, Sierra and Jennings 2002) used a given linearly addictive multi-attribute utility function to represent agent preferences. Each agent is assumed to have a scoring function that gives the score it assigns to a value of each decision variable in the range of its acceptable values. Then the agent assigns a weight to each decision variable to represent its relative importance. (Lin, et al. 2008) assumed that agents have bounded rationality and their choice preferences are modeled using the a utility function generated from the order of ranking of different offers. The analysis is shifted from the model of expected utility maximization to the evaluation of offers using the maximin method and the ranking of offers.

A number of papers, however, represent the trade-off between multiple issues using constraints instead of utility functions. (Balakrishnan and Eliashberg 1995) propose a single-issue negotiation process model where the utilities are simply the negotiation outcome, and agents' dynamic preferences are represented using a constraint with the left-hand side denoting agents' "resistance forces", and right-hand side "concession forces". (Luo, et al. 2003) consider fairness using a fuzzy constraint based model for bilateral, multi-issue negotiations in trading environments. The prioritized fuzzy constraints are used to represent trade-offs between the different possible values of the negotiation issues and to indicate how concessions should be made when they are necessary.

\subsection{Agent-Internal States}

Agent-internal states, consisting of the more affective aspects of negotiator behavior, such as trust, moods or emotions, have become a popular venue of re- 
search in the recent years after a long-lasting reluctance to grant them a place at the bargaining table. This growing body of research has convincingly drawn attention to the importance of these concepts in shaping not only negotiators' own but also perceptions of others' states and consequently influencing bargaining behavior (Kumar, 1997; Barry and Oliver, 1996). The field has also outlines a distinction between the different types of affective states that may be in play during negotiation (or before and after as well). Affect refers to the "whole range of preferences, evaluations, moods and emotions" (Watson and Tellegen, 1985, as quoted in Thompson, 1998). Moods are "low-intensity, diffuse and relatively enduring affective states" and which influence "a whole range of social cognitions and behaviors considered to be primarily positive or negative" (Thompson, 1998). Finally, emotion "refers to the complex assortment of affects, beyond merely good feelings and bad that include several feelings of states" (Thompson, 1998). As can be understood from these definitions, affective states such as emotions and moods, though they certainly influence cognitions, are still understood as separate processes from them, which is a distinction that was not clearly delineated for many years in negotiation literature.

Most of the affect work in negotiation has been on the positive side and the general finding has been that positive emotions lead to a range of positive outcomes. Kramer and colleagues (1993) have found that when happy negotiators bargain with other happy negotiators, their individual outcomes are better. Carnevale and Isen (1986) replicate this finding at the joint outcome level and also find that happy negotiators perform better mainly because they engage in less contentious tactics and pressure their counterparts less towards concessions. On the other hand, there has been less research on the role of negative or neutral emotions in negotiation, owing partly to the relative difficulty of experimentally manipulating negative emotions such as anger, sadness, guilt or shame. Methods traditionally used to induce positive feelings such as making the participants watch happy videos before the negotiation do not work as effectively when applied to the negative realm. That being said, there is also considerable consensus in the field that negotiation with positive emotions lead to better outcomes than those with negative emotions (Forgas, 1998; Van Kleef, De Dreu, and Manstead, 2003). For example, angry negotiators have been found to claim more value (Anderson and Neale, 2007); to force their opponents into more concession making (Sinaceur and Tiedens, 2006) and to have outcome preferences with deleterious effects on the overall negotiation process (Loewenstein, Thompson, and Bazerman, 1989). Another point about work on negative emotion in negotiation is that most of it has been in comparative terms to negative emotions such as happy vs. sad or neutral negotiators. Therefore, the field is certainly open to expansion of knowledge how, under what conditions and through which mediators negative and neutral emotions influence bargaining situations.

In computational literature, there is a lack of modeling efforts in terms of subjective agent characteristics such as beliefs, prejudices, emotions and cultural factors. Most of the existing models, however, clearly specify information disclosure within negotiating agents, i.e., who knows what, who understands what. 
(Kraus, Wilkenfeld and Zlotkin 1995) assume that each agent knows all relevant information about the other agent, particularly internal state and utility function over different outcomes. (Lin, et al. 2008) assume that there is a finite set of agent types. Each agent is aware of the set of possible types of the opponent but not the exact utility function. The agent has some probabilistic belief about the type of the other agent and such beliefs can be updated throughout the negotiation process. (Busch and Horstmann 2002) study a two-issue bargaining model with asymmetric information to study agent choice of how to structure bargaining. The problem involves a buyer and a seller who bargain over the price of two distinct goods (X and Y). The seller's valuation for each good is public knowledge; the buyer's valuation of $\mathrm{X}$ is common knowledge, but his valuation of $\mathrm{Y}$ is private information. The seller updates his belief each time after he receives an offer from the buyer.

\subsection{Agent-Internal Reasoning}

The third category, agent-internal reasoning encompasses the cognitions and the entailing behaviors that negotiators engage in as they search for information with the aim of sense-making during bargaining. Commonly referred to as the cognitive approach, this perspective posits that cognitive activity can be broken down and analyzed in terms of how negotiators process and recode abstract information. Some of the most popular subjects of bargaining research such as biases, heuristics or interpersonal attributions and judgments fall under the umbrella of this perspective before the evolution of which, the field had been more interested in untangling the basic behaviors, goals and strategies of negotiators without dwelling much into their underlying processes. Building on prospect theory and behavioral decision theory, the cognitive approach in negotiation has demonstrated strong effects of biases such as availability, anchoring and overconfidence. For instance, Galinsky and colleagues (2002) find that initial offers negotiators make serve as anchors that eventually become more influential assessments of outcome satisfaction than objective results are. In a similar way, building on information-processing theory, there have been findings on the implications of how the negotiation task or process is perceived by the negotiators. For example, Ross and Samuels (2003) demonstrated the influence of task perception on negotiator behavior with a very simple manipulation. They basically named two prisoner's dilemma scenarios that are similar in all other aspects in competitive vs. cooperative terms to find that that negotiators act in line with the names. All these findings show that how negotiators perceive the bargaining situation and the actors within the bargaining situation has the potential to exert process and outcome changing influence.

There exists a comprehensive body of computational literature of agentinternal reasoning. (Zeng and Sycara 1998) deveop an automated negotiation model wherein agents are capable of reasoning based on experience and improve their negotiation strategies incrementally. They utilize the Bayesian framework to update an agent's belief about its opponents. (Lin, et al. 2008) model an agent's internal reasoning in terms of generating and accepting offers. When 
generating offers, an agent selects the best offer among the offers that the agent believes might be accepted. To be more specific, the agent selects the minimum value of 1) the agent's own estimation of the offer and 2) the agent's estimation of its opponents' acceptable offer, under the pessimistic assumption that the probability that an offer is accepted is based on the agent that favors the offer the least. In discussing the agent's reasoning about accepting offers, they make the assumption that each offer is evaluated based on their relative values compared to the reservation price. (Luo, et al. 2003) express agents' preferences as "Prioritized Fuzzy Constraint Satisfaction Problems", wherein agents optimize their objective values given constraints with different priority levels. This model is the basis for the buyer agent and the seller agent to reason about generating and accepting offers during the negotiation process. (Faratin, Sierra and Jennings 2002) model agents' trade-offs between various offers/outcomes using similarity-based trade-off reasoning. A linear trade-off algorithm is proposed to represent agents' preferences.

\subsection{Externally-Observable Behavior and Characteristics}

The final category of the framework is the externally-observable behavior and characteristics such as strategies, tactics and outcomes of negotiation. As how behavioral sciencists approach negotiation outcomes has been dealt with in the general review section, it is more useful in this part to try to delineate how negotiators employ strategies and tactics to reach these outcomes. For clarity of concepts, it is necessary to point out that behavioral research treats tactics and strategies differently as tactics are negotiation behaviors "employed in service of a goal" which is a very broad concept but one which is used "not in isolation but rather in combination, either consciously or unconsciously to form a strategy" (Weingart and Olekans, 2003). With this definition, it is possible to think of how almost all the concepts that have so far been described in this framework can be utilized for tactical purposes or become part of an overall negotiation strategy. As such, negotiation researchers have examined how emotions can be used as a tactic or how perception of other side's utility is a determinant on individual bargaining strategies. Another line of research within this category has been concerned with examining tactics and strategies within the negotiation process and how they consequently relate to the outcome as opposed to linking them directly to outcomes. An example would be process research that looks at how negotiators' tactical knowledge influences the frequency of the tactical use of this knowledge (Weingart, Hyder and Prietula, 1996).

Computational researchers, on the other hand, has been focusing on agents' optimal actions based on their reasoning strategies, and the efficiency compared to Pareto optimal solutions or human negotiation outcomes. (Faratin, Sierra and Jennings 2002) provided conditions for convergence of optimal strategies, and negotiation outcomes for different scenarios. (Lai, Sycara, and Li, 2008) proposed a protocol that can not only assist agents to make offers efficiently in the $n$-dimensional space but also give agents sufficient decision flexibility. They showed their efficiency of negotiation outcome by comparing with Pareto 
equilibrium results. There has been consistent evidence that using an intelligent agent to negotiate with a human counterpart achieves significantly better outcomes than negotiation between two human beings (Lin et al., 2008; Kraus et al. 2008). While the results are encouraging, several complexities restricts their significance: 1) Implementation of the computational model. It remains challenging to illicit human preferences in multiple issues. 2) Information exchange mechanism. Computational negotiation agents might not be able to exchange information as efficiently as human beings in occasions accurate representations are hard to achieve. 3) How "efficient" the negotiation outcome ultimately depends on human affects and cultural factors, which have not been taken into account by the existing computational researchers.

\section{Conclusions}

In this paper, we provided a selective review of two streams of negotiation literature: artificial intelligence and behavioral sciences. We first discuss their key differences and similarities in focus, methodology, and forms of presentation. Then we put the literature in a unified framework under which we summarized how the existing work in both of the two fields treat these four categories. We identify various opportunities to leverage the richness of knowledge in the behavioral literature and the detailed modeling of agent decision making, aiming to consolidate negotiation work that could address more realistic and challenging negotiation situations. At this point, it is useful to suggest some concrete ways in which these two literature can enhance each other. As it has been pointed out earlier in the paper, findings from the behavioral literature have been richer in quantity and in complexity. It is thus logical to suggest that the quantitative findings from this literature should be used to inform computational research on negotiation. More specifically, behavioral literature can shed light on how people behave in various bargaining contexts where there is the additional complexity of emotion, stereotyping prejudice and many other similar factors. It is our belief that computational research can use these findings to take negotiation research to the next frontier of capturing uniquely human dimensions, which are very relevant in an interaction such as negotiation. It is also our contention that this point is especially important for culture research, where there is variation across and within culture as well as with regards to the topics being examined.

\section{Acknowledgement}

This research was funded by ARO grant W911NF0810301.

\section{References}

1. Anderson, C., and Shirako, A. Are Individuals Reputations Related to Their History of Behavior? Journal of Personality and Social Pyschology, (2008): 320-333. 
2. Bac, Mehmet, and Horst Raff. Note: Issue-by-issue negotiations: the role of information and time preference. Games and Economic Behavior 13 (1996): 125-134.

3. Bandura, A. (1977). Self-efficacy: Toward a unifying theory of behavioral change. Pyschological Review , 191-215.

4. Barry, B., and Oliver, L. (1996). Affect in Dyadic Negotiation: A Model and Propositions. Organizational Behavior and Human Decision Processes , 127-143.

5. Balakrishnan, P.V., and Jehoshua Eliashberg. An analytical process model of twoparty negotiation. Management Science 41, no. 2 (1995): 226-243.

6. Bensaid, Bernard, and Robert J. Gary-Bobo. An exact formula for the lion's share: a model for preplay negotiation. Games and Economic Behavior 14 (1996): 44-148.

7. Bolton, Gary E., Kalyan Chatterjee, and Kathleen L. McGinn. How communication links influence coalition bargaining: a laboratory investigation. Management Science 49, no. 5 (2003): 583-598.

8. Braun, Peter, Jakub Brzostowski, Gregory Kersten, Jin Baek Kim, Ryszard Kowalczyk, Stefan Strecker and Rustam Vahidov. e-Negotiation Systems and Software Agents: Methods, Models and Applications. In Intelligent Decision-making Support Systems, Springer London, (2006): 271-300

9. Busch, Lutz-Alexander, and Ignatius J. Horstmann. The game of negotiations: ordering issues and implementing agreements. Games and Economic Behavior 41 (2002): 169-191.

10. Curhan, J. R., Elfenbein, H., and Xu, H. (2006). What Do People Value When They Negotiate? Mapping the Domain of Subjective Value in Negotiation. Journal of Personality and Social Pyschology , 493-512.

11. De Drue, C., Weingart, L., and Kwon, S. (2000). Influence of Social Motives on Integrative Negotiation: A Meta-Analytic Review and Test of Two Theories. Journal of Personality and Social Psychology , 889-905.

12. Deutsch, M. (1949). A Theory of Competition and Cooperation. Human Relations , 199-231.

13. Druckman, D. (1986). Stages, Turning Points and Crises: Negotiating Military Base Rights, Spain and the United States. The Journal of Conflict Resolution , 327-360.

14. Faratin, P., C. Sierra, and N. R. Jennings. Using similarity criteria to make issue trade-offs in automated negotiations. Artificial Intelligence 142 (2002): 205-237.

15. Fatima, Shaheen S., Michael Woodldridge, and Nicholas R. Jennings. An agendabased framework for multi-issue negotiation. Artificial Intelligence 152 (2004): 1-45.

16. Forgas, J. (1998). On feeling good and getting your way: Mood effects on negotiator cognition and bargaining strategies. Journal of Personality and Social Psychology , 129-151.

17. Hanaki, Nobuyuki, Alexdander Peterhansl, Peter S. Dodds, and Duncan J. Watts. Cooperation in Evolving Social Networks. Management Science 53, no. 7 (2007): 1036-1050.

18. Kersten, Gregory E., Wojtek Michalowski, Stan Szpakowicz, and Zbig Koperczak. Restructrable representations of negotiations. Management Science 37, no. 10 (1991): 1269-1290.

19. Kraus, Sarit, Negotiation and cooperation in multi-agent environments. Artificial Intelligence 94 (1997): 79-97.

20. Kraus, Sarit, Jonathan Wilkenfeld, and Gilad Zlotkin. Multiagent negotiation under time constraints. Artificial Intelligence 75 (1995): 297-345.

21. Kraus, Sarit, Penina Hoz-Weiss, Jonathan Wilkenfeld, David R. Andersen, and Amy Pate. Resolving crises through automated bilateral negotiations. Artificial Intelligence 172 (2008): 1-18. 
22. Kraus, S., Sycara, K. and Evanchik, "Argumentation in Negotiation: A Formal Model and Implementation", Artificial Intelligence, (104)1-2, pp. 1-69, September 1998.

23. Kumar, R. (1997). The role of affect in negotiations. Journal of Applied Behavioral Science, 84-100.

24. Lai, Guoming, Cuihong Li, Katia Sycara, and Joseph Giampapa. Literature review on multi-attribute negotiations. Technical report, Robotics Institute, Carnegie Mellon University, 2004.

25. Lai, G., C. Li, and K. Sycara. Efficient Multi-attribute Negotiation with Incomplete Information. In the journal of Group Decision and Negotiation. Vol. 15 (5), 511-528, September 2006.

26. Lai, G. Sycara, K, Li C. A Decentralized Model for Automated Multi-attribute Negotiations with Incomplete Information and General Utility Functions. Journal of Multi Agent and Grid Systems, 4, No. 1, (2008): 39-57.

27. Lai, G. and Sycara, K. A Generic Framework for Automated Multi-Attribute Negotiation, Group Decision and Negotiation, doi10.1007/s10726-008-9119-9, ISSN 09262644 (Print) 1572-9907 (Online), July 31, 2008.

28. Lange, A., and Vogt, C. (2003). Cooperation in international environments due to a preference for equity. Journal of Public Economics , 2049-2067.

29. Laruelle, Annick, and Federico Valenciano. Cooperative bargaining foundations of the Shaply-Shubik index. Games and Economic Behavior 65 (2009): 242-255.

30. Li, C., Giampapa, J., Sycara, K. Bilateral Contract Negotiation Decisions with Uncertain Dynamic Outside Options, IEEE Systems, Man and Cybernetics, Part C., special issue on Game Theoretic Analysis and Stochastic Simulation of Negotiation Agents, Vol. 36, No 1, pp. 1-13, 2006.

31. Lin, Raz, Sarit Kraus, Jonathan Wilkenfeld, and James Barry. Negotiating with bounded rational agents in environments with incomplete information using an automated agent. Artificial Intelligence 172 (2008): 823-851.

32. Loewenstein, G., Thompson, L., and Bazerman, M. (1989). Social utility and decision making in interpersonal contexts. Journal of Personality and Social Pyschology , 426-441.

33. Luo, Xudong, Nicholas R. Jennings, Nigel Shadbolt, Ho-fung Leung, and Jimmy Ho-man Lee. A fuzzy constraint based model for bilateral, multi-issue negotiations in semi-competitive environments. Artificial Intelligence 148 (2003): 53-102.

34. McGinn, K., and Keros, A. (2002). Improvisation and the Logic of Exchange in Socially Embedded Transactions. Administrative Science Quarterly , 442-473.

35. Myerson, R. B. (1977). Two-Person Bargaining Problems and Comparable Utility. Econometrica , 1631-1637.

36. Nash, J. (1953). Two-person cooperative games. Econometrica , 128-140.

37. Nicolo, Antonio, and Yan Yu. Strategic divide and choose. Games and Economic Behavior 64 (2008): 268-289.

38. O'Neill, Barry, Dov Samet, Zvi Wiener, and Eyal Winter. Bargaining with an agenda. Games and Economic Behavior 48 (2004): 139-153.

39. Pruitt, D., and Rubin, J. (1986). Social Conflict: Escalation, Stalemate and Settlement. New York: Random House.

40. Raiffa, H. The Art and Science of Negotiations, Belknay/Harvard University Press, Cambridge, MA, 1982.

41. Ramchurn, Sarvapali D., Carles Sierra, Lluis Godo, and Nicholas R. Jennings. Negotiation using rewrads. Artificial Intelligence 171 (2007): 805-837. 
42. Rangaswamy, Arvind, and G. Richard Shell. Using computers to realize joint gains in negotiations: toward an "electronic bargaining table". Management Science 43, no. 8 (1997): 1147-1163.

43. Rao, Ambar G., and Melvin F. Shakun. A normative model for negotiation. Management Science 20, no. 10 (1974): 1364-1375.

44. Sebenius, James K. Negotiation analysis: A characterization and review. Management Science 38, no. 1 (1992): 18-38.

45. Sycara, Katia. Persuasive argumentation in negotiation. Theory and Decision 28, no. 3 (1990): 203-242

46. Sycara, Katia P. Problem Restructuring in Negotiation. Management Science 37, no. 10 (1991): 1248-1268.

47. Synder, C., and Higgins, R. (1988). Excuses Their Effective Roles in the Negotiation of Reality. Pyschological Bulletin , 23-45.

48. Thompson, L. (1998). The Mind and Heart of the Negotiator. New York: Prentice Hall.

49. Van Kleef, G. A., De Dreu, C., and Manstead, A. (2003). The Interpersonal Effects of Anger and Happiness on Negotiation Behavior and Outcomes. IACM 15th Annual Conference.

50. Van Lange, P. A. (1999). The Pursuit of Joint Outcomes and Equality in Outcomes:An Integrative Model of Social Value Orientation. Journal of Personality and Social Psychology , 337-349.

51. Zeng, D, and K Sycara. Bayesian learning in negotiation. International Journal of Human-Computers Studies 48, no. 1 (1998): 125-141.

52. Zlotkin, Gilad, and Jeffrey S. Rosenschein. Compromise in negotiation: exploring worth functions over states. Artificial Intelligence 84 (1996): 151-176. 


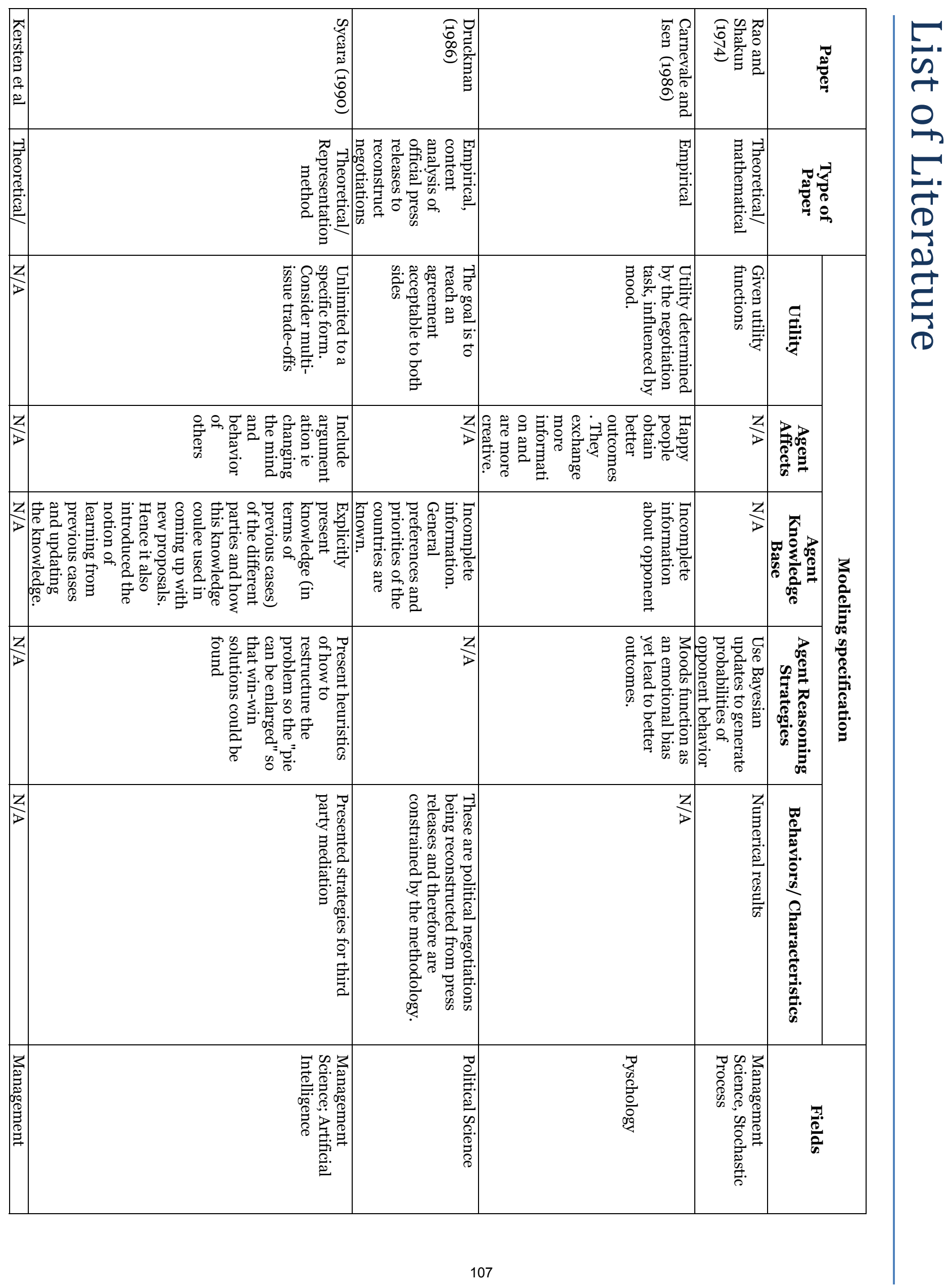




\begin{tabular}{|c|c|c|c|c|c|c|c|}
\hline 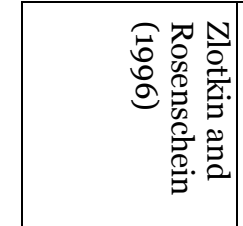 & 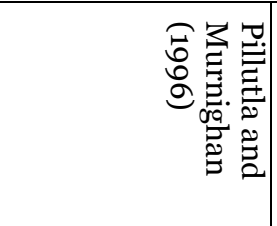 & 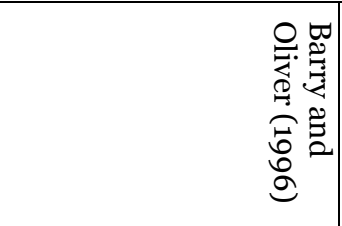 & 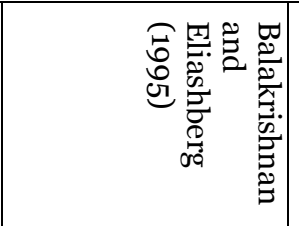 & 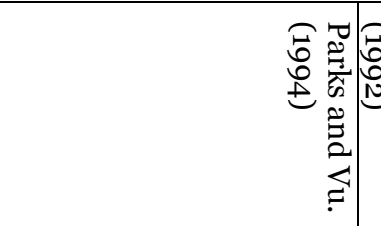 & & 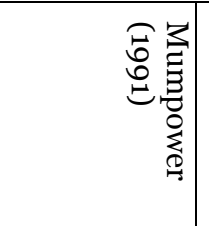 & 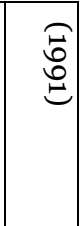 \\
\hline 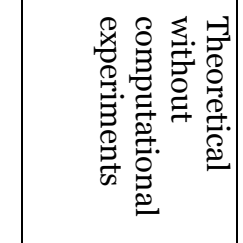 & $\begin{array}{l}\text { : } \\
: \\
: \\
:\end{array}$ & 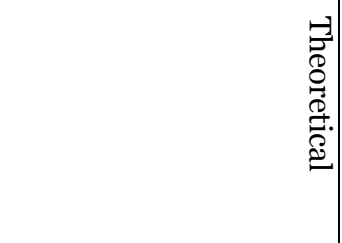 & 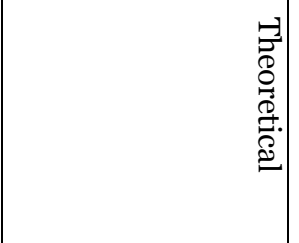 & 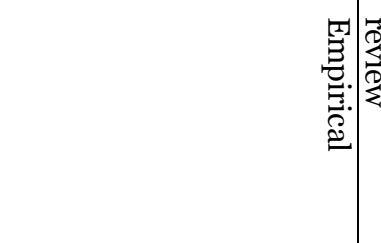 & | & 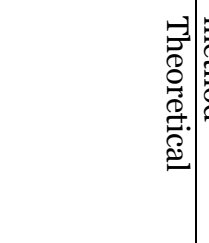 & 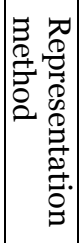 \\
\hline 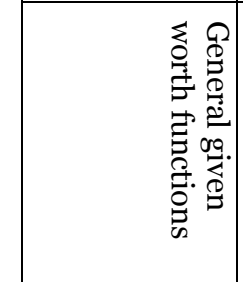 & 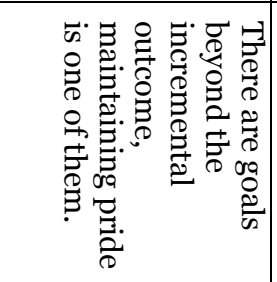 & 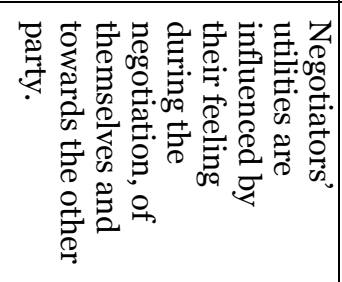 & 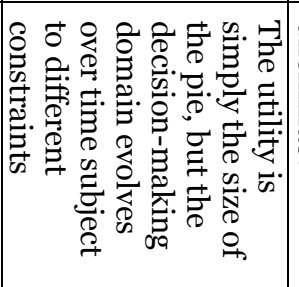 & 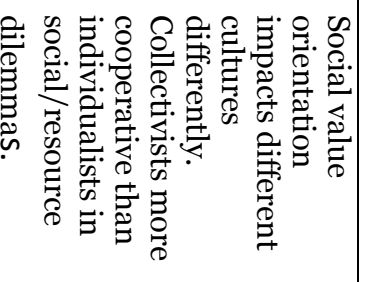 & $\frac{z}{p}$ & 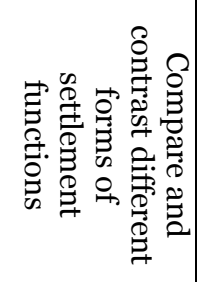 & \\
\hline$\frac{z}{s}$ & 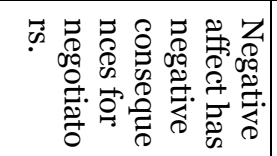 & 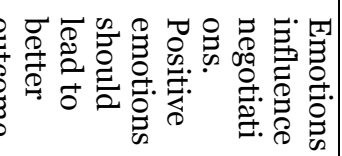 & $\frac{z}{p}$ & $\frac{z}{p}$ & & 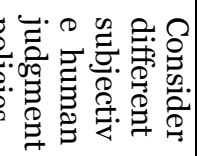 & \\
\hline 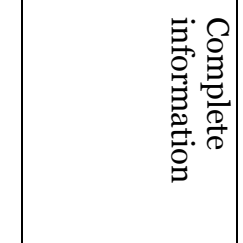 & 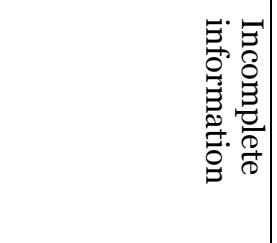 & 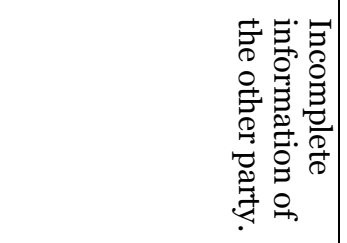 & 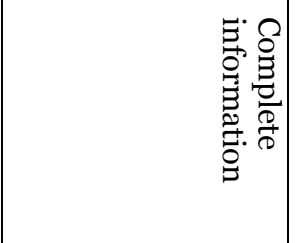 & 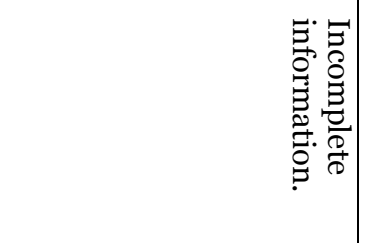 & $\frac{z}{p}$ & $\frac{\mathbb{Z}}{\mathrm{p}}$ & \\
\hline 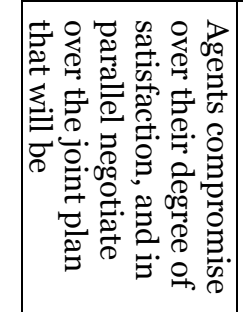 & 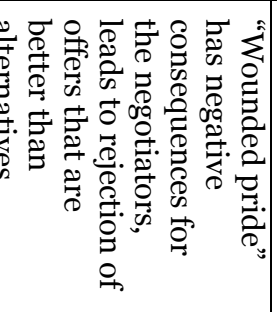 & $\frac{z}{p}$ & 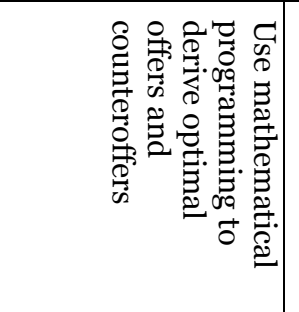 & 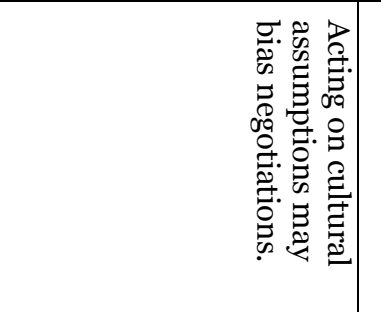 & $\frac{z}{p}$ & 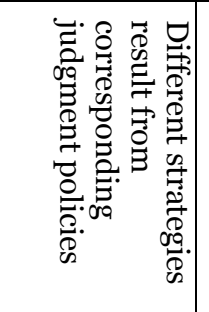 & \\
\hline$\frac{z}{p}$ & $\frac{z}{p}$ & $\frac{z}{p}$ & 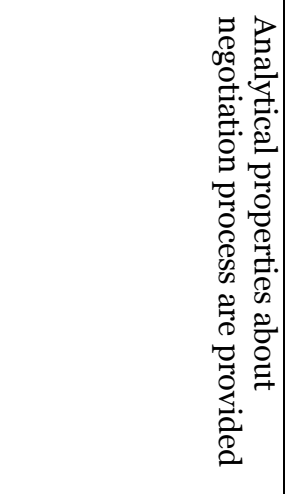 & $\frac{z}{p}$ & $\frac{z}{p}$ & 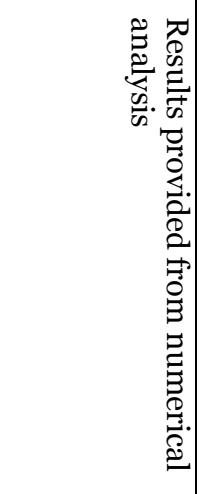 & \\
\hline 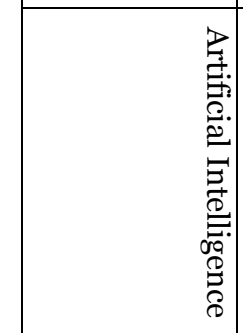 & 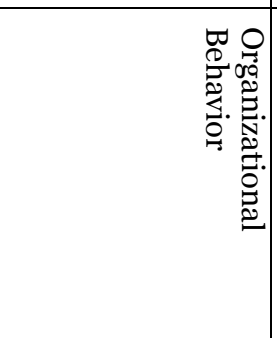 & 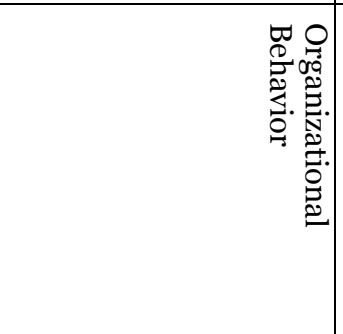 & 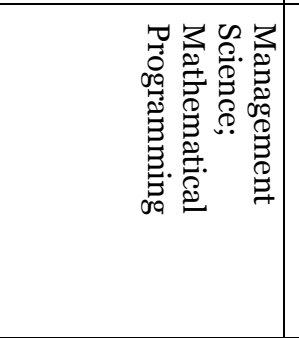 & 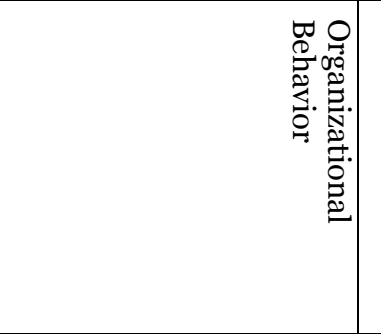 & 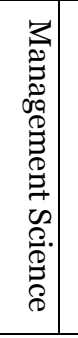 & 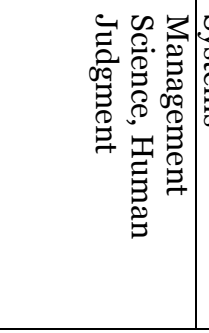 & 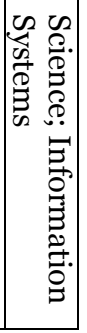 \\
\hline
\end{tabular}




\begin{tabular}{|c|c|c|c|c|c|}
\hline 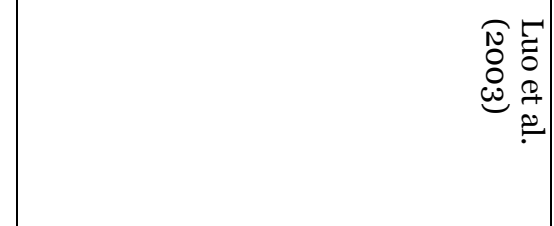 & 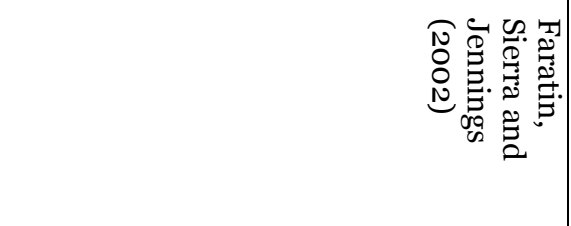 & 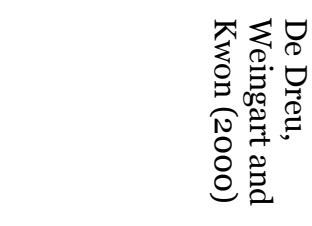 & 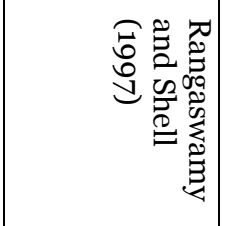 & 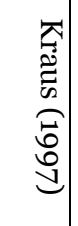 & \\
\hline 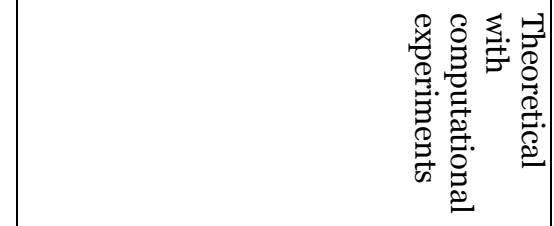 & 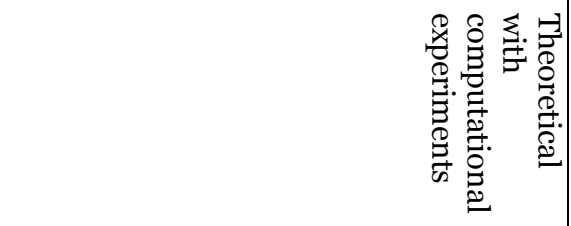 & 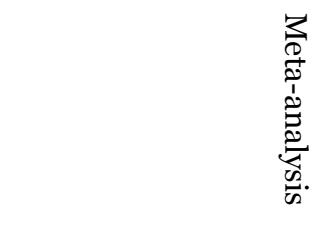 & 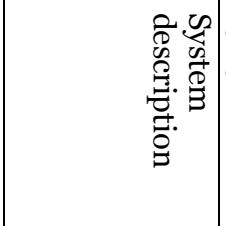 & 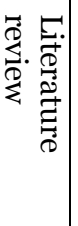 & \\
\hline 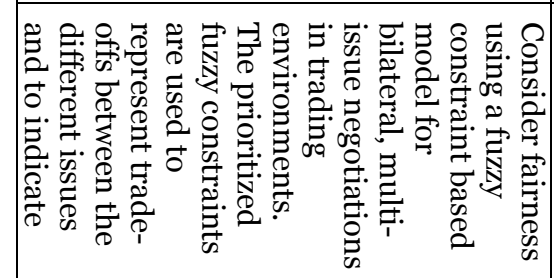 & 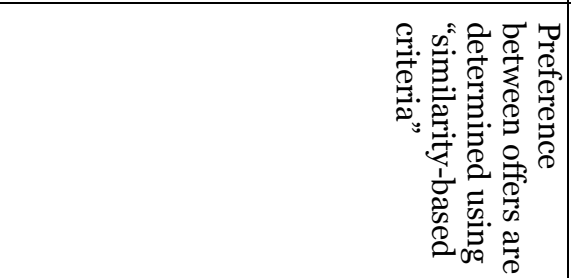 & 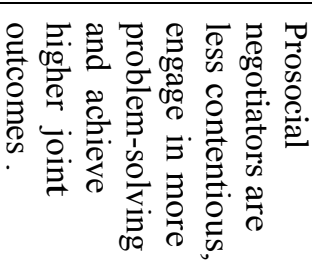 & 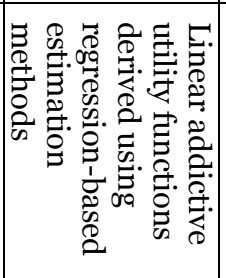 & $\frac{z}{p}$ & \\
\hline$\frac{z}{p}$ & $\frac{z}{p}$ & $\frac{z}{p}$ & $\frac{z}{D}$ & $\frac{Z}{p}$ & \\
\hline 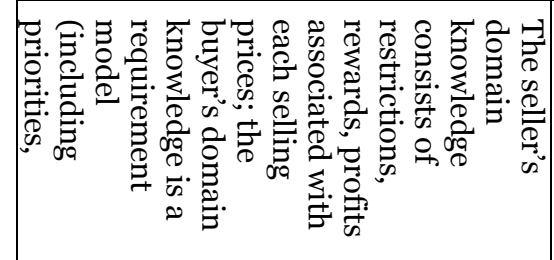 & 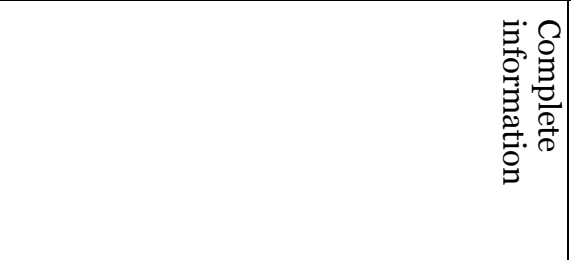 & $\frac{z}{j}$ & 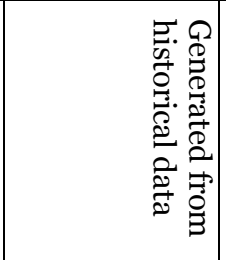 & $\frac{z}{s}$ & \\
\hline 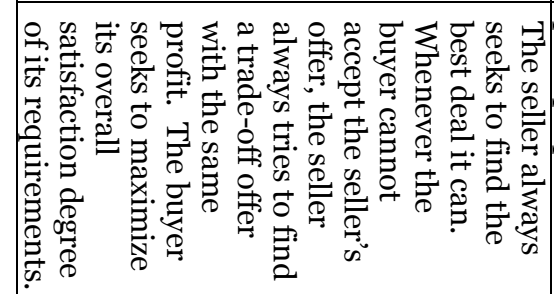 & 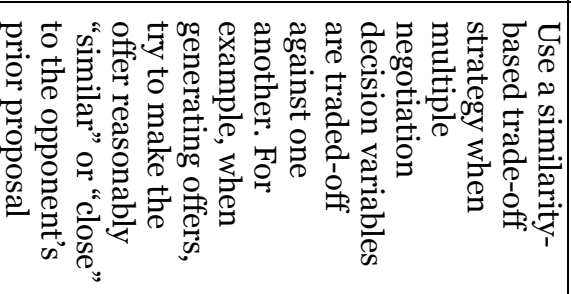 & $\frac{z}{p}$ & $\frac{z}{p}$ & $\frac{z}{p}$ & 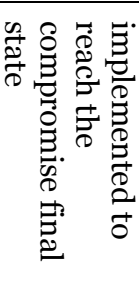 \\
\hline 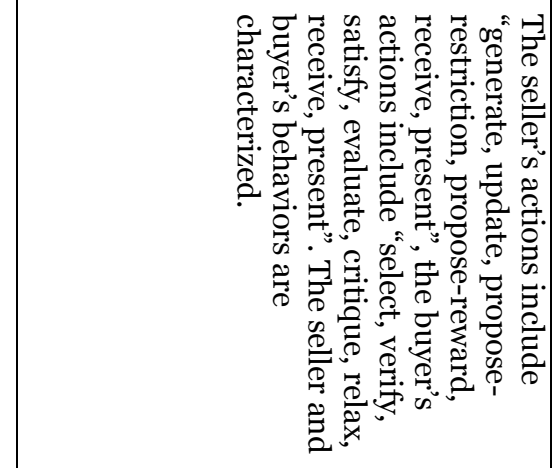 & 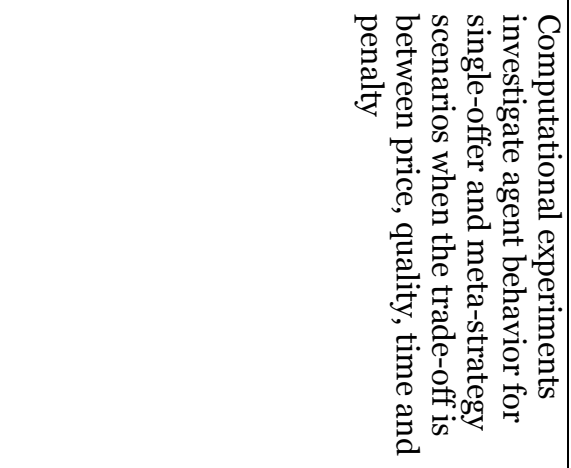 & $\frac{z}{p}$ & $\frac{z}{s}$ & $\frac{z}{p}$ & \\
\hline 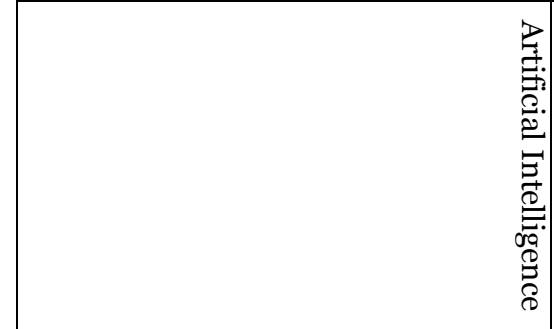 & 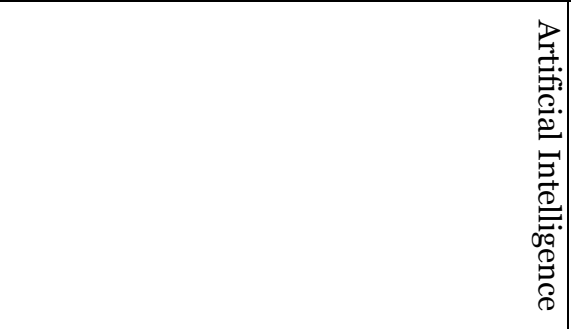 & 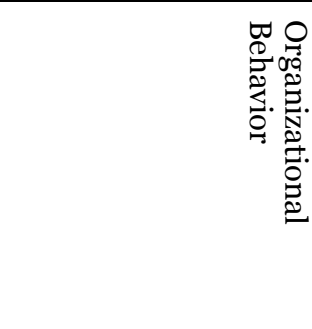 & 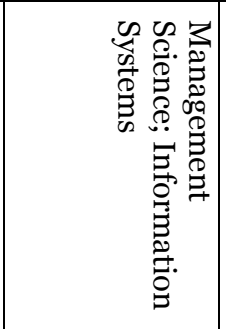 & 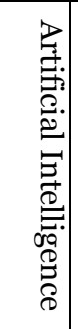 & \\
\hline
\end{tabular}




\begin{tabular}{|c|c|c|c|c|}
\hline 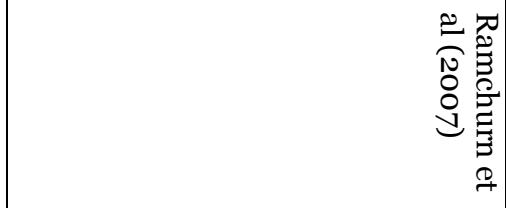 & 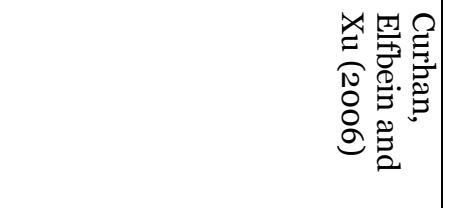 & 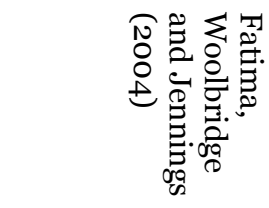 & 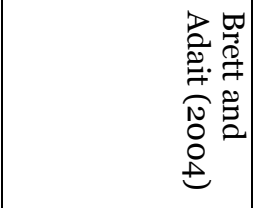 & \\
\hline 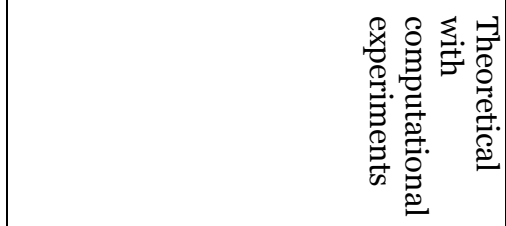 & 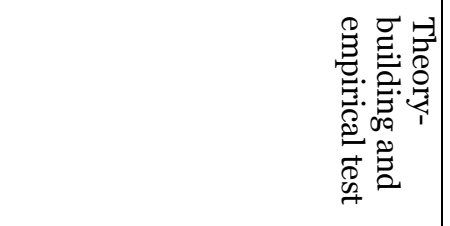 & 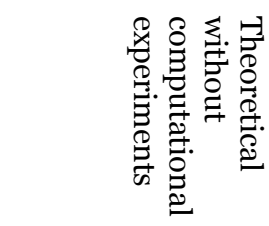 & 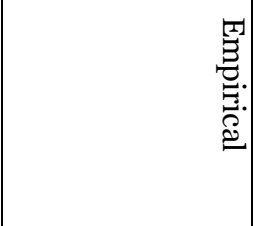 & \\
\hline 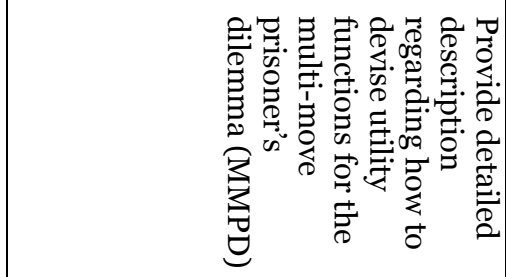 & 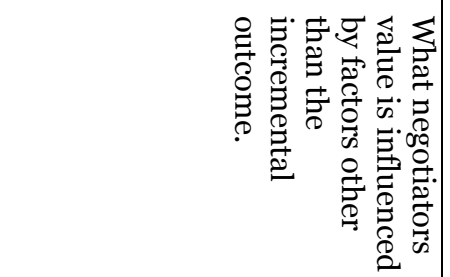 & 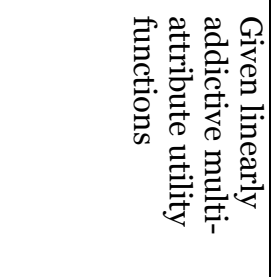 & 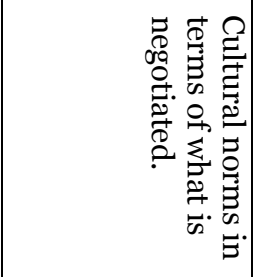 & 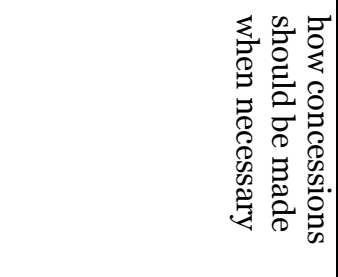 \\
\hline$\frac{z}{p}$ & 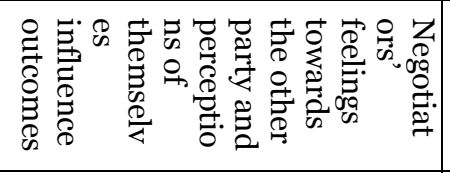 & $\frac{z}{s}$ & $\frac{z}{s}$ & \\
\hline 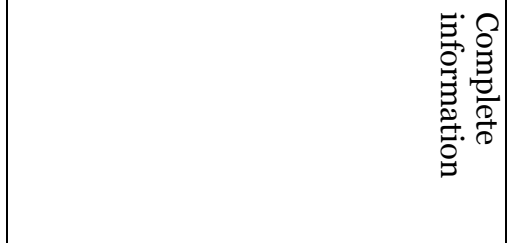 & 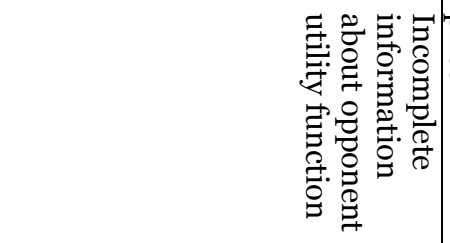 & 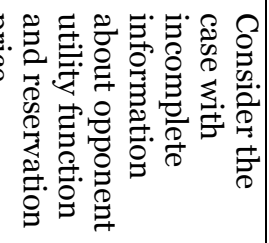 & 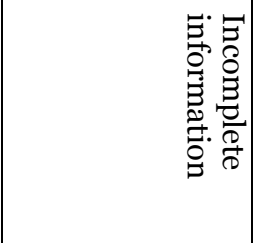 & 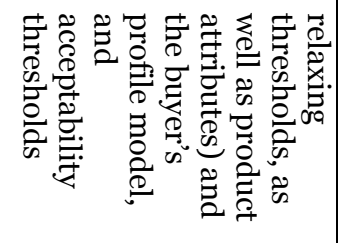 \\
\hline 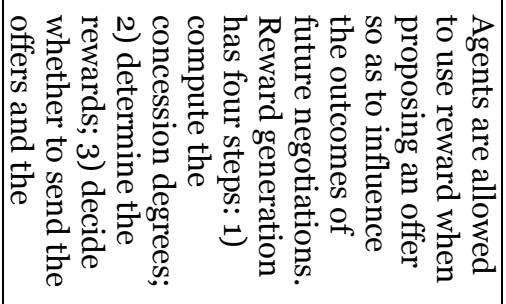 & & 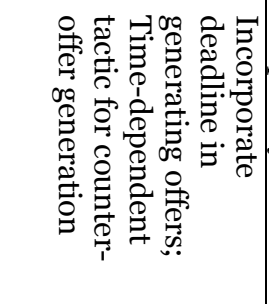 & 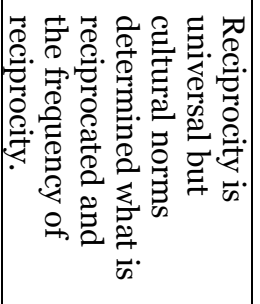 & 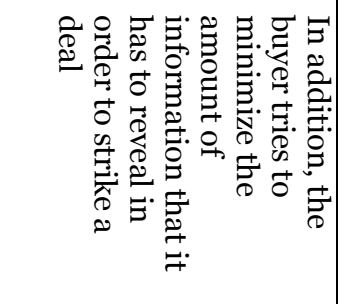 \\
\hline 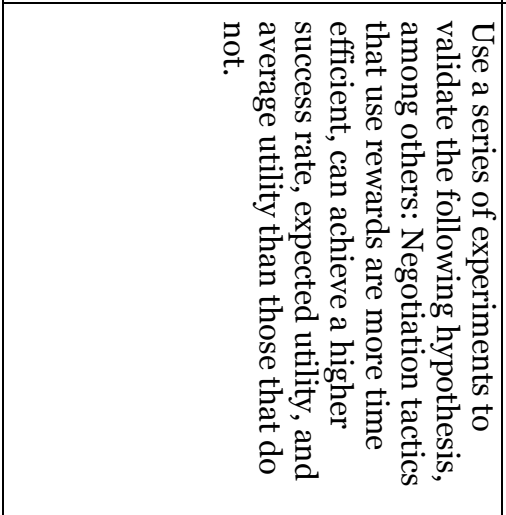 & 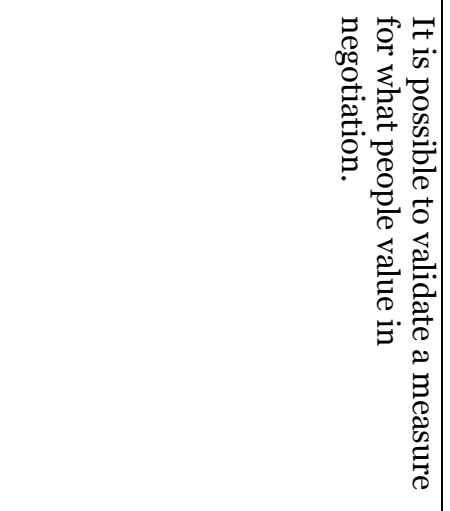 & 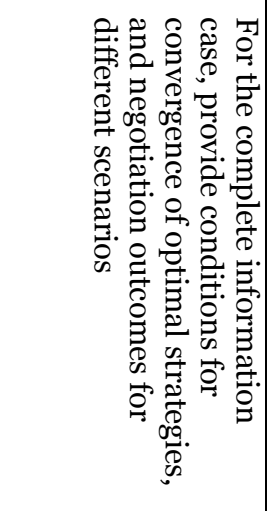 & $\frac{z}{p}$ & \\
\hline 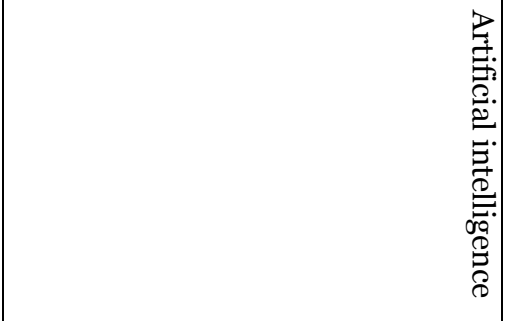 & 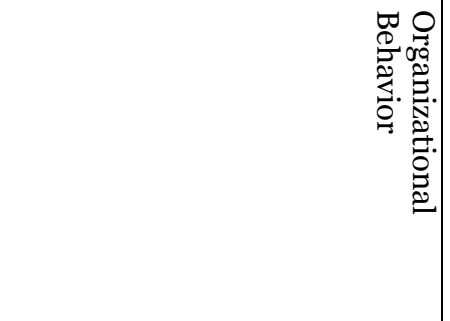 & 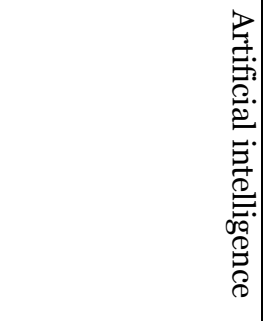 & 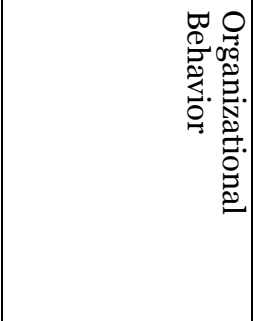 & \\
\hline
\end{tabular}




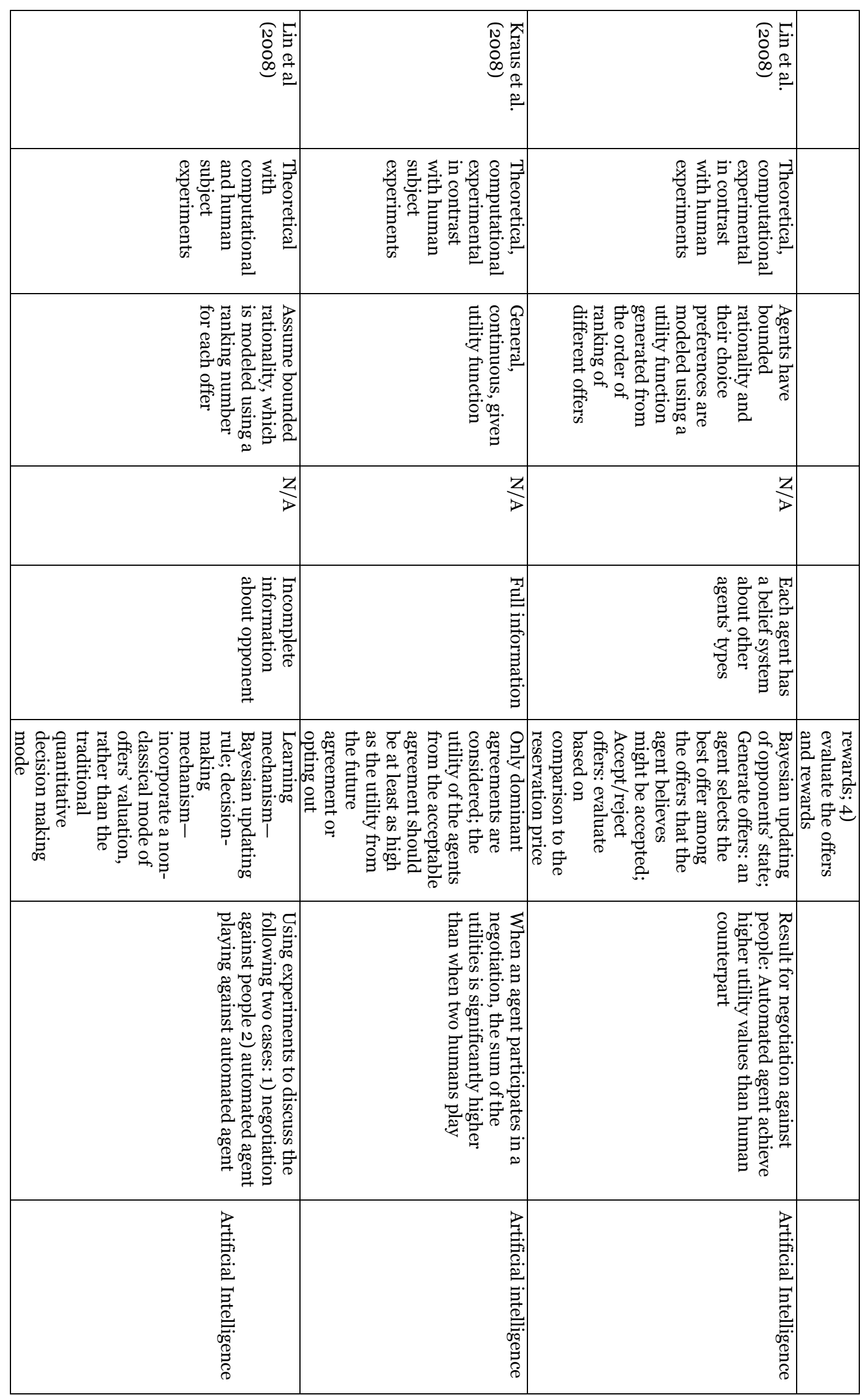

